\title{
Improving the Vocabulary Mastery in ELT Context: Mapping Words Technique for Vocational Students
}

\author{
Sitti Aisyah \& Novalia Tanasy \\ Universitas Muslim Maros, Maros. Indonesia \\ novalia@umma.ac.id
}

\begin{abstract}
ARTICLE HISTORY
Received : 2021-03-09

Revised : 2021-03-21

Accepted : 2021-06-02
\end{abstract}

\section{KEYWORDS}

Vocabulary Mastery

ELT

Mapping Words Technique

Pre-test

Post-test

Vocational Students

\begin{abstract}
This modern era, people are demanded to have more than one language especially English as an international language. In educational context, developing the students' ability to master English, it cannot be separated from vocabulary mastery because it can be a measurement of students, understanding of English. This research is conducted to determine the implementation of mapping words technique effectiveness in improving the student's vocabulary mastery at the third Year Students of SMK Darussalam Makassar. This quasiexperimental research used two group designs named pre-test and post-test. 60 out of 287 students as being registered as a sample. The experimental group consists of 32 students, and the control group consists of 28 students. This research applied the Mapping Words technique as the medium while the other class using the conventional method. The result of this research showed that the use of the Mapping Words technique effectively improves the students' vocabulary, it was shown from the result of pre-test and post-test in both groups. The mean scores and standard deviation of the experimental class showed improvement where the two mean scores' deviation 27,11 was $/ 16,96$. The value of the t-test was 4.37, while the value of the t-table was 2.021 on the level of significant $0.05(95 \%)$ and 2.704 on the level significant 0.01 (99\%). This figure indicated that the value of t-calculated was higher than the $t$-value of t-table $4.37>2.021$ and 2.704 .
\end{abstract}

\section{Introduction}

People in the modern era are expected to have more than one language, which serves as a medium for communication and plays an important role in daily activities. We will be left behind if we do not communicate in a foreign language because communication in a foreign language is a bridge to information, knowledge, and culture. As a developing country, Indonesia has recognized the importance of English as an International language for Indonesians to learn.

English must be taught to young people, in this case students from elementary school to senior high school. It cannot be distinguished from vocabulary mastery in improving students' ability to master English as it can be a measurement of students' comprehension of the language. Vocabulary is one of the language components which has a role in the development of language skills because of the huge majority of learners, the ultimate goal of studying is able to communicate (Sunubi, 2018).in second or foreign language learning, vocabulary is considered as one of necessary factors (Sari and Stupo, 2018). Teaching vocabulary can be accomplished in a variety of ways, one of which is by incorporating mapping terms into teaching activities.
In this case, students are allowed to find similar words that are related to the key phrase. They can work in groups or on their own. They learn to share knowledge and ideas about targeted material, and they do so happily because it is the next step of the class activity. Students' knowledge of English vocabulary can be improved indirectly by using the mapping word technique in the classroom. At the very least, it will improve their self-confidence in expressing themselves freely, particularly during speaking practice. Students should share their information and experiences with others, including appropriate listening and sharing personal viewpoints. Students also reported that their understanding of concepts was expressed and considered. Students have claimed that their interpretation of concepts was articulated and taken into account.

Moreover, at the very least, we hope that students will be able to not only broaden their vocabulary but also practice communicating and knowing the meaning of words. Further, based on the researcher's research at SMK Darussalam Makassar, mapping words is a suitable technique for secondary students to develop their vocabulary mastery. To be proved how far the mapping word could be influenced students' vocabulary skill. 
Echoing the previous ideas and claims, this study aims to expand and highlighting the relevant ideas regarding the methodology on applying mapping words and its effect on increasing students' vocabulary skills. Therefore, this research was conducted to answer whether the implementation of mapping words technique effective to improve the student's vocabulary at the Third Year Students of SMK Darussalam Makassar?

\section{Literature Review}

\subsection{The Definition of Vocabulary}

Suryana, in Teaching Vocabulary (1990) states that vocabulary is one of the language components. It supports the teaching and learning of the four language skills of reading, listening, speaking, and writing (Sunubi, 2018). Vocabulary, as a language component, must be properly taught. He also notes in his book that vocabulary is divided into :

a) Vocabulary Skill involved deducing meaning from the context, Use of Dictionary, word formation coining, and ignoring unfamiliar words.

b) Vocabulary activities involved word guessing, word association, crossword puzzles, cline, wordclassification, and rid dies.

The ways of teaching vocabulary are commonly noted in the teaching of vocabulary concept as follows:

a) Pre-teaching (relate to the text)

1) The word cannot be deduced from the text

2) Keywords

b) Stand Alone

1) Select new vocabulary items from the previous text

2) Add some more new words

3) Give an explanation using the technique we have

4) Followed by practice and use

a) How Teach Vocabulary Integratively?

b) In Training Plan for LKI and LKGI, Suryana $(1997: 1)$ explores that teaching vocabulary integrative, as follows:

1) Brainstorming

2) Discussion

3) Explanation/Conclusion

4) Analyzing

5) Designing

6) Indirect vocabulary learning

c) Children learn word meanings indirectly in three ways:

1) They engage daily in oral language

2) They listen to adults read to them

3) They read extensively on their own.
Children learn a lot of new vocabulary by reading a lot on their own. The more children read on their own, the more words they come across and the more word meanings they learn.

\subsection{The Definition of Mapping Words Technique}

One practice that can help students develop their English vocabulary is mapping words. It also teaches one of the most important methods of incorporating language skills in the language classroom. Though the terms 'mapping words' and 'mapping skills' have been interpreted in a variety of ways by teachers and textbook researcher, both practices include a versatile yet principled method of tailoring intergraded skills to learner needs.

McDonough (2004) states that: "Network vocabulary and simulation work, on the other hand, typically require learners to participate in communication that includes personal experience and emotion."

\subsubsection{The effectiveness of the Mapping Words Technique according to the Experts}

According to Carter et al. (1988, p.12) states:

"The lists include a word from the target language, a synonym in that language, or a translation in the mother tongue, and these may be followed by an image or other graphic or mnemonic representation". While according to Aston (1982): "Mapping Words activities can involve practice, especially, although by no means exclusively, where younger learners are involved." From the statements above, the researcher concludes that speaking exercises focused on graphics are frequently a valuable way of providing students with valuable practice, whether in the classroom or outside.

The relationship between the Mapping Words and its effect to improve student's skill in mastering vocabulary, Nunan (1991) states that " This exercise is also a good way to practice conversational listening skills so the listener will ask for clarification if anything is unclear."

We usually write in a linear progression or manner. However, according to Kurtus (2003), the problem is that the mind's creative part does not come up with ideas linearly. During the creative process, the mind often jumps from one stage to another. While researcher often use a linear outliner, such as MS Word, to help organize their thoughts, studies have shown that people do not often think in this manner. Usually, innovative ideas come to us in spurts, jumping from one subject to the next. Thus, a multidimensional graphical outline, which helps the students to put down their thoughts in the form of free-association diagrams, is preferable to a linear outline. This graphical outline method is called Mindmapping. 
According to some studies, Buzan and Buzan (2000) first introduced Mind-mapping, but mind mapping has been used even before Buzan popularized it. According to Jonassen et al. (1997), it is known by several other names, such as "semantic networking" and "concept maps," used by the Institute for the Advancement of Research in Education (IARE) (2003). Mind-mapping is the visual representation of connected thoughts that are based on a given idea or topic. This visual representation includes words, lines, colors, and images, stimulating the brain and allowing individuals to visualize related ideas. Mind mapping has four characteristics:

a) A central image represents the subject.

b) The main themes of the subject radiate from the central image as main branches.

c) Significant themes are linked to the main themes.

d) All the branches are connected, forming a nodal structure.

We have known what mind-mapping is and its characteristics, now we have a look at the Step of creating the mind-map:

a) Begin with the main topic;

b) Write some of the significant, essential subheadlines;

c) Link these two additional sub-sub-headlines;

Repeat steps 2 and 3 until your outline is completed; To have more explanation about how to Produce a mind-map, we have the following examples. As can be seen, the mind map begins with the main topic, "Uses of mind maps," in the centre. Smaller sub-topics surround the primary topic. For instance, mind maps can help us decide, take notes, creativity, problem-solving, plan, and public speaking. As items are called out, they are strung out from the centre bubble "Uses of mind maps."

Moreover, for each sub-topic, additional topics are included. For example, thanks to mind maps, we can make decisions in our projects, meetings, teams, prioritizing, etc. Moreover, to distinguish words, we use bubbles, different types of lines, pictures, and colors.

\subsubsection{The Phase of Mapping Words in Teaching Vocabulary}

A model for structuring Word activities in the classroom is offered by Herbert and Sturtridge (1979). In this case, they state that "The framework integrates the aforementioned versatility in terms of how assignments can be graded, the teacher's position during the exercise, and the type of material to be used." They suggest three-phase sequences for staging Mapping words techniques in teaching vocabulary they are:

a) First-phase; The informational feedback can take the form of memorizing to read or it can be based on listening. . b) Second-phase; the information that other learners have similar concerning some of the measures above and very different in another case.

c) The third- phase, The feedback process must be treated carefully so that it does not turn into a pessimistic account of what went wrong. For error analysis, it may be possible to report on general types of errors made in the community, as well as where and how communication broke down, and provide learners with individualized feedback.

\section{Method}

The method that used in this research was the descriptive quasi-experimental method, where it applied in two groups of pre-test and post-test design based on Arikunto (2013). This quasi-experimental method is divided into two groups, experimental groups and control groups. The experimental class applied this treatment by mapping words, and the control class did not apply this treatment mapping words. In this research, the researcher tried to determine the significance between experimental class and control class after using this method of mapping words.

\subsection{Population and Sample}

According to Ali (1992, p.5), "If the sample represents the population, what is known about the sample is our knowledge of the population. The implication is, if the research used represents the population, so done generally to the population". While according to Arikunto (1998, p.115-117), "Population is the whole of the research subject, whereas sample is a part of the population."

In this case, the researcher have chosen the third grade of SMK Darussalam Makassar, the population of the study was 287 students in the third grade, but the sample is 60 students from class XII-1 as the experimental and XII-2 as the control class.

The sample to be investigated is taken randomly. The sample is 32 students as the experimental or as an experimental group. In this case, the researcher chose 28 students as the control group.

The place of research conducted by the researcher is SMK Darussalam Makassar. To collect the objective data, the researcher will apply the steps as follows: (1) Observation or analysis is a measurement operation that requires the use of instruments or questions to collect data. The researcher noticed items related to the research process that can help the data's outcome, such as the state of the class, the student's capacity in English ability or the population's condition, the technique of teaching vocabulary, the material, and the realia used in the class. (2) Vocabulary Test which consists of Pre-test; the first test before the researcher applies the method teaching vocabulary by using the Mapping Words technique, and Post-test; the second test after the 
researcher applied the method teaching of vocabulary by using the Mapping words technique, to know how far distinction of developing student's mastery in vocabulary.

\subsection{Data Analysis Procedure}

Based on the research method that will be carried out in experimental research methodology, so the researcher will analyze the data by using the formula explained by Suharsimi Arikunto as follows:

Where:

$\mathrm{t}=$ Test score
$\mathbf{M}=$ Mean of each group

$\mathbf{N}=$ Number of subjects

$\mathbf{X}=$ Deviation of $\mathrm{X} 1$ and $\mathrm{X} 2$

$\mathbf{Y}=$ Deviation of $\mathrm{Y} 1$ and $\mathrm{Y} 2$

\section{Findings}

Findings In the process of analyzing the data, the researcher firstly computed the deviation scores of pre-test and post-test of individual samples for each class and then followed computation of mean scores of the sample of each class. The two mean scores were compared by employing the formula which previously asserted.

Table 1. The Deviation Scores of Pre-Test and Post-Test (Experimental)

\begin{tabular}{|c|c|c|c|c|}
\hline Student Number & Pre-test & Post-test & $(\mathbf{X})$ & $\left(\mathbf{X}^{2}\right)$ \\
\hline 1 & 48,4 & 72,3 & 23,9 & 571,21 \\
\hline 2 & 41,4 & 64,3 & 22,9 & 524,41 \\
\hline 3 & 41,4 & 54,1 & 12,7 & 161,29 \\
\hline 4 & 26,4 & 69,1 & 42,7 & 1823,29 \\
\hline 5 & 21,2 & 69,3 & 48,1 & 2313,61 \\
\hline 6 & 56,6 & 66,7 & 10,1 & 102,01 \\
\hline 7 & 31,6 & 60,7 & 29,1 & 846,81 \\
\hline 8 & 42,2 & 64,9 & 22,7 & 515,29 \\
\hline 9 & 52,4 & 66,9 & 14,5 & 210,25 \\
\hline 10 & 34,8 & 64,9 & 30,1 & 906,01 \\
\hline 11 & 44,2 & 66,9 & 22,7 & 515,29 \\
\hline 12 & 34,4 & 58,9 & 24,5 & 600,25 \\
\hline 13 & 38,4 & 62,3 & 23,9 & 571,21 \\
\hline 14 & 37,2 & 48,9 & 11,7 & 136,89 \\
\hline 15 & 42,0 & 64,3 & 22,3 & 497,29 \\
\hline 16 & 39,4 & 61,9 & 22,5 & 506,25 \\
\hline 17 & 27,0 & 64,3 & 37,3 & 1391,29 \\
\hline 18 & 34,6 & 64,3 & 29,7 & 882,09 \\
\hline 19 & 37,0 & 61,7 & 24,7 & 610,09 \\
\hline 20 & 39,6 & 61,7 & 22,1 & 488,41 \\
\hline 21 & 24,4 & 66,7 & 42,3 & 1789,29 \\
\hline 22 & 24,4 & 61,7 & 37,3 & 1391,29 \\
\hline 23 & 26,8 & 61,7 & 34,9 & 1218,01 \\
\hline 24 & 21,6 & 61,7 & 40,1 & 1608,01 \\
\hline 25 & 29,0 & 53,7 & 24,7 & 610,09 \\
\hline 26 & 49,8 & 66,9 & 17,1 & 292,41 \\
\hline 27 & 27,0 & 64,3 & 37,3 & 1391,29 \\
\hline 28 & 32,2 & 64,3 & 32,1 & 1030,41 \\
\hline 29 & 29,6 & 64,3 & 34,7 & 1204,09 \\
\hline 30 & 44,6 & 61,9 & 17,3 & 299,29 \\
\hline 31 & 21,6 & 61,3 & 39,7 & 1576,09 \\
\hline 32 & 42,2 & 53,9 & 11,7 & 136,89 \\
\hline $\mathrm{N}=32$ & \multicolumn{2}{|c|}{ TOTAL } & $x=867,4$ & $x^{2}=26720$ \\
\hline
\end{tabular}


Table 2. The Deviation Scores of Pre-Test and Post-Test (Control Class)

\begin{tabular}{|c|c|c|c|c|}
\hline Students Number & Pre-test & Post-test & $(\mathbf{Y})$ & $\left(\mathbf{Y}^{2}\right)$ \\
\hline 1 & 26,8 & 54,1 & 27,3 & 745,29 \\
\hline 2 & 24 & 36,5 & 12,5 & 156,25 \\
\hline 3 & 29,2 & 44,3 & 15,1 & 228,01 \\
\hline 4 & 21,6 & 38,9 & 17,3 & 299,29 \\
\hline 5 & 26,6 & 44,3 & 17,7 & 313,29 \\
\hline 6 & 31,8 & 49,5 & 17,7 & 313,29 \\
\hline 7 & 19 & 28,5 & 9,5 & 90,25 \\
\hline 8 & 29,2 & 56,9 & 27,7 & 767,29 \\
\hline 9 & 26,6 & 46,7 & 20,1 & 404,01 \\
\hline 10 & 19,2 & 46,7 & 27,5 & 756,25 \\
\hline 11 & 26,6 & 38,9 & 12,3 & 151,29 \\
\hline 12 & 14 & 36,7 & 22,7 & 515,29 \\
\hline 13 & 19 & 36,5 & 17,5 & 306,25 \\
\hline 14 & 21,6 & 33,9 & 12,3 & 151,29 \\
\hline 15 & 26,6 & 41,7 & 15,1 & 228,01 \\
\hline 16 & 19 & 31,5 & 12,5 & 156,25 \\
\hline 17 & 21,6 & 41,7 & 20,1 & 404,01 \\
\hline 18 & 19 & 36,5 & 17,5 & 306,25 \\
\hline 19 & 8,8 & 21,1 & 12,3 & 151,29 \\
\hline 20 & 16,4 & 56,9 & 40,5 & 1640,25 \\
\hline 21 & 21,4 & 39,1 & 17,7 & 313,29 \\
\hline 22 & 26,6 & 33,9 & 7,3 & 53,29 \\
\hline 23 & 26,6 & 34,1 & 7,5 & 56,25 \\
\hline 24 & 31,8 & 49,3 & 17,5 & 306,25 \\
\hline 25 & 18,8 & 26,3 & 7,5 & 56,25 \\
\hline 26 & 21,6 & 31,5 & 9,9 & 98,01 \\
\hline 27 & 19,2 & 39,1 & 19,9 & 396,01 \\
\hline 28 & 26,6 & 38,9 & 12,3 & 151,29 \\
\hline $\mathrm{N}=\mathbf{2 8}$ & TO & & $y=474,8$ & $=9514,04$ \\
\hline
\end{tabular}

d. $\quad \sum \mathrm{y}=\sum \mathrm{y}^{2}-$

$\frac{2 y)^{2}}{N y}=9514,04-\frac{(474,8)^{2}}{28}=9514,04-$ $\mathrm{Ny}$
$8051,25=1462,79$

a. $\quad \mathrm{Mx}=\frac{\overline{\sum x}}{N}=\sqrt{\frac{867,4}{32}=27,11}$

b. $\mathrm{My}=\frac{\sum y}{N}=\frac{474,8}{2.8}=16,96$

c. $\quad \sum x=\sum x^{2}-$

$\frac{(2 x)^{2}}{N x}=26720,4-\frac{(6667)^{2}}{32}=26720,4-$

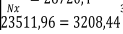

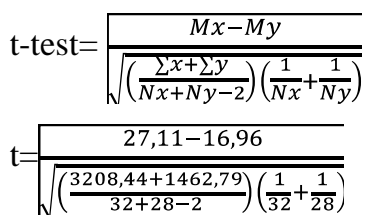


$\mathrm{t}=\sqrt{\frac{10,15}{\sqrt{(5,39)}}}$

$\mathrm{t}=\frac{10,15}{2,32}$

$\mathrm{t}=4,37$

The data analysis in this study was ultimately aimed at determining the deviation means ratings. It was referred to as the t-test score, which was 4,375 . Now, the score is used to determine whether or not the study is significant.

\section{Discussion}

Before the researcher checked the table of the $t$ distribution, in the first instance, the researcher determined the degree of freedom ( $(\mathrm{df}) \operatorname{viz}\left(\mathrm{N}_{\mathrm{x}}+\mathrm{N}_{\mathrm{y}}-\right.$ 2 ) or $32+28-2=58$. Based on the table of level significance have been pointed out, the coefficient ( $t$ test) was directly checked on the table of the $t$ distribution.

Derived from the table, the critical value of the $t$ table on the level significance t 0.05 was 2.021 , and 0.01 was 2.704; it was found that the t-test was higher than the t-table $(4.37>2.021$ and 2.704$)$. Thus, there was a significant difference in the student's vocabulary between the experimental and control class. From the result, it was found that t-test was 4.37 and the degree of freedom (df) employed in this research was interpreted more to compare with two critical values: t-test and table. This research's degree of freedom can be obtained from the formula $\mathrm{N}_{\mathrm{x}}+\mathrm{N}_{\mathrm{y}}$ $-2=32+28-2=58$. The researcher employed the degree of freedom 58 as the nearest of the degree of freedom 58 was 2.021 from the confidence level of $0.0595 \%$ and 2.704 from the confidence level of 0.01 $99 \%$.

Based on the data analysis above, it was found that the result of the t-test was higher than the t-table. It means that alternative hypothesis $\left(\mathrm{H}_{\mathrm{a}}\right)$, which asserted that there is an effect on the Word Mapping Technique in Teaching Vocabulary, is accepted, whereas the null hypothesis $\left(\mathrm{H}_{\mathrm{o}}\right)$ asserted that it is not effective on the Word Mapping Technique in Teaching Vocabulary is rejected.

This findings seems in line with Sunubi (2018) study which found that there was an improvement of the students' vocabulary mastery after gving the learning process by using concept mapping strategy. Another findings has been found by Sari and Sutopo (2018), the statistical analysis of their research showed there is an interaction among vocabulary teaching strategies, metacognitive awareness and vocabulary mastery. Generally, the results of this research indicated that mapping words can be an appropriate strategy to improve students; vocabulary mastery.

\section{Conclusion}

Based on the data analysis explained in chapter IV, the researcher can conclude that the word mapping technique effectively teaches vocabulary. It provides both the mean scores and standard deviation of the experimental class showed that it was more effective than the control class. The deviation of the two mean scores $(27,11 / 16,96)$ was also significant. It read that the value of the t-test was 4.37 while the value of the t-table was 2.021 on the level of significant 0.05 (95\%) and 2.704 on the level significant 0.01 (99\%). This figure indicated that the value of t-calculated was higher than the t-value of t-table $4.37>2.021$ and 2.704 .

According to the researcher's conclusion, a teacher should be more innovative in teaching English in the classroom so that students have fun and enjoy the learning process. When teaching, the instructor can use exciting and current media, as well as the mind mapping technique to help students develop their vocabulary. It is because this approach is useful to them, and the second recommendation for students is to enrich their English vocabulary through technology such as watching television, Twitter, or other social media, or through nontechnology such as reading a book, newspaper, magazine, etc., and to always or should pay attention when your teacher discusses the lesson.

\section{References}

Arikunto, S. (1998). Prosedur penilaian. Jakarta: Rineka Cipta.

Arikunto, S. (2013). Manajemen Penelitian edisi duabelas. Jakarta: Rineka Cipta.

Arikunto, S. (2013). Metode Penelitian kuantitatif kualitatif dan R\&D. Alfabeta: Bandung.

Aston, G. (1982). Interact: An Interaction Workbook. Modern English Publications.

Baker, J., \& Westrup, H. (2000). English Language Teacher's Handbook: How to Teach Large Classes with Few Resources. Bloomsbury Publishing.

Buzan, T., \& Buzan, B. (2000). The mind map book (Millenium ed.)

Carter, R., McCarthy, M., Channell, J., \& McCarthy, M. (1988). Vocabulary and language teaching (pp. 68-75). London: Longman.

Chamot, A . U., Barnhardt, S., El-Dinary, P., \& Robbins, J. (1999). The learning strategies handbook. White Plains, NY: Addison-Wesley Longman.

Cross, D. (1995). A Practical Handbook of Language Teaching (pp. 543-547). Hertfordshire: Phoenix EL. 
Davies, P., \& Pearse, E. (2000). Success in English Teaching: A Complete Introduction to Teaching English at Secondary School Level and Above. Oxford University Press.

Gairns, R., and Redman, S. (1991). Working with words. Cambridge University Press. Heinemann.

Gower, R., Phillips, D., and Walters, S. (Eds.). (2005). Teaching Practice Handbook. Cambridge University Press.Macmillan.

Harmer, J. (2001). The practice of English language teaching. longman.

Hornby, A. S., \& Cowie, A. P. (1995). Oxford advanced learner's dictionary (Vol. 1430). Oxford: Oxford university press.

Jonassen, D. H., Reeves, T. C., Hong, N., Harvey, D., \& Peters, K. (1997). Concept mapping as cognitive learning and assessment tools. Journal of interactive learning research, 8(3), 289.

McDonough, K. (2004). Learner-learner interaction during pair and small group activities in a Thai EFL context. System, 32(2), 207-224.

Nunan, D. (1991). Communicative tasks and the language curriculum. TESOL quarterly, 25(2), 279-295.

Sturtridge, G., \& Herbert, D. (1979). Simulations. NFER for English Language Teaching Institute.

Sunubi, A. H. (2018). Increasing Vocabulary Mastery of The First Year Students of Smp Negeri 3 Pamboang Through Concept Mapping Strategy. Inspiring: English Education Journal, 1(2), 25-39.

Suryana, D. (1990). Teaching Vocabulary. Bandung. UPI

Ur, P. (2012). A course in English language teaching. Cambridge University Press. 